\title{
Sensoriamento remoto aplicado ao estudo de densidade demográfica
}

\author{
Alex Mota dos Santos, Fabrizia Gioppo Nunes, Rodrigo Lima Santos
}

https://doi.org/10.4322/mp.978-65-991393-8-3.c1

\section{Resumo}

O mapeamento de densidade demográfica é recorrente nas análises geográficas, suas aplicações são variadas e representa a relação do número de habitantes por uma determinada área, que geralmente poder ser: um país, estado, município, bairro, setor censitário, dentre outras. Assim, a densidade demográfica é critério fundamental para a compreensão da dinâmica populacional, sedo um índice adotado por diversos países em diferentes continentes. Contudo, o Método Coroplético, que é clássico e de uso recorrente na espacialização de densidade demográfica revela que a população está distribuída homogeneamente em cada unidade de área, mesmo quando partes da região é, na realidade, desabitada. Desse modo, esse capítulo apresenta o Método Dasimétrico, que é uma alternativa para estimar a localização mais realista da ocupação humana para o cálculo de densidade demográfica, dentro da unidade de área a ser adotada. Para tanto, emprega-se o processamento de imagens de sensoriamento remoto orbital em ambientes de sistemas de informação geográfica. Os resultados indicam as áreas construídas, onde se localizam os habitats urbanos, enquanto "principal tarefa geográfica". Além disso, contribui para pensar o urbano na sua dimensão sócio-espacial, como o modo pelo qual a reprodução do espaço se realiza na contemporaneidade, como realidade e como possibilidade. Assim, quando identificadas áreas densamente povoadas é possível observar impactos sociais, ambientais e econômicos, especialmente com maiores riscos de degradação ambiental, criminalidade e sobrecarga da infraestrura viária. Por fim, sob a perspectiva do método, a experiência tem revelado resultados de densidades demográficas mais realísticas com tendência de aumento do teor de seus valores nas cidades brasileiras.

Palavras-chave: dasimetria, geografia urbana, processamento digital de imagem, urbanização.

\section{Introdução}

O mapeamento de densidade demográfica é recorrente nas análises geográficas, suas aplicações são variadas e representa a relação do número de habitantes por uma determinada área, que geralmente poder ser: um país, estado, município, bairro, setor censitário, dentre outras. Uma das primeiras representações de densidade demográfica, foi feita pelo Método Coroplético, que pode ser observada no mapa de Dupin, ainda em 1826 [1].

A importância do mapeamento de densidade demográfica está relacionada ao fato de que é necessário determinar a representação precisa da população total e da distribuição de subpopulações específicas para áreas urbanas [2]. As representações dessa natureza são importantes nos estudos da geografia urbana, em setores 
direcionados a: saúde pública, saneamento, moradias, mobilidade urbana, crimes e ambiental. Além disso, para [3], muitos tipos de análises de política urbana, particularmente aquelas relacionadas à exposição a perigos ou acessibilidade a recursos, dependem de dados da distribuição espacial da população, de forma exata e precisa, embora esses dados nem sempre estejam disponíveis.

Na ciência geográfica, existe uma tradição antiga relativa aos estudos urbanos, vários destes lançando as bases para o pensamento urbano brasileiro [4-12]. Tais alicerces, possibilitaram 0 avanço e ampliação das bases teórico-metodológicas do conhecimento urbano.

Entretanto, foi somente a partir do início do século $\mathrm{XXI}$, que vários trabalhos começaram a se preocupar em agregar novas ferramentas aos estudos urbanos, especialmente aquelas provenientes do avanço das técnicas de sensoriamento remoto [13-21]. Alguns dos fatores responsáveis por esse avanço são: (i) a disponibilidade de dados em quantidade e qualidade de forma gratuita; (ii) a ampliação das resoluções, espectrais, espaciais e temporais; (iii) o acesso à Sistemas de Informação Geográfica SIG open source e; (iv) a evolução dos algoritmos de processamento de dados.

Essas possibilidades, abrem amplos caminhos para a realização de mapeamentos sistemáticos das áreas urbanas brasileiras, em especial aquelas mais recentemente constituídas como capitais estaduais planejadas e que passaram por processos recentes de expansão. Assim, amplia-se o foco em diferentes problemáticas e mesmo aos estudos de modelagem urbana, que visem a projeção de cenários futuros onde 0 fator densidade demográfica é importante [22-26].

Nesse sentido, o Método Coroplético, que é clássico e de uso recorrente na espacialização da densidade demográfica revela que a população está distribuída homogeneamente por toda a área, mesmo quando partes da região é, na realidade, desabitada. Por outro lado, os estudos sobre mapeamentos de densidade através do Método Dasimétrico estão se tornando cada vez mais recorrentes, em várias partes do mundo [2, 3, 27, 28]. Desse modo, esse capítulo esmera em apresentar o Método Dasimétrico, que é uma alternativa para estimar a localização mais realista da ocupação humana para o cálculo de densidade demográfica, dentro da unidade de área a ser adotada.

De modo geral, os autores que aplicaram este método são enfáticos ao afirmarem que, pelo Método Dasimétrico, os resultados de densidades demográficas são mais realistas e com tendência de aumento do teor de seus valores. Segundo Mennis [29], - Método Dasimétrico envolve a desagregação dos dados populacionais, codificados em forma de mapa coroplético, usando um conjunto de dados geográficos complementares, a exemplo, das imagens de satélite.

Desta forma, as imagens de sensoriamento remoto, sejam orbitais, suborbitais ou terrestres, adequadamente processadas, oferecem recursos tecnológicos para desagregação de áreas habitadas em áreas urbanas. Isso ocorre, pois, dependendo da resolução espacial, que indica o detalhamento dos alvos na imagem, os produtos de sensoriamento remoto permitem identificar com maior precisão as áreas habitadas dentro de uma cidade. Aplicações semelhantes foram apresentadas por [30-32], o que permitiu aos autores deste capítulo, o acúmulo de experiências de aplicações dessa metodologia.

Mesmo assim, e apesar de seu potencial, observa-se que ainda são poucas as cidades analisadas por esse método. Diante de tal constatação, o objetivo desse capítulo é apresentar um roteiro técnico-metodológico de aplicação do Método 
Dasimétrico, para o cálculo de densidade demográfica, dentro da unidade de área a ser adotada, que nesse estudo foi a cidade de Palmas, capital do estado do Tocantins.

\section{Material e Métodos}

Como área de estudo para a aplicação da análise da densidade demográfica foram selecionados os setores censitários da cidade de Palmas, capital do estado de Tocantins (TO), situada na porção centro norte do Brasil (Figura 01). Considerada como a maior cidade de TO, em termos de urbanização e em número de habitantes, Palmas, segundo o último censo demográfico do Instituto Brasileiro de Geografia e Estatística [33], possuía uma população de 228.332 habitantes (hab.). População esta, distribuída por uma área de $2.227,45 \mathrm{~km}^{2}$ que the conferia uma densidade demográfica de 102,90 hab./km².

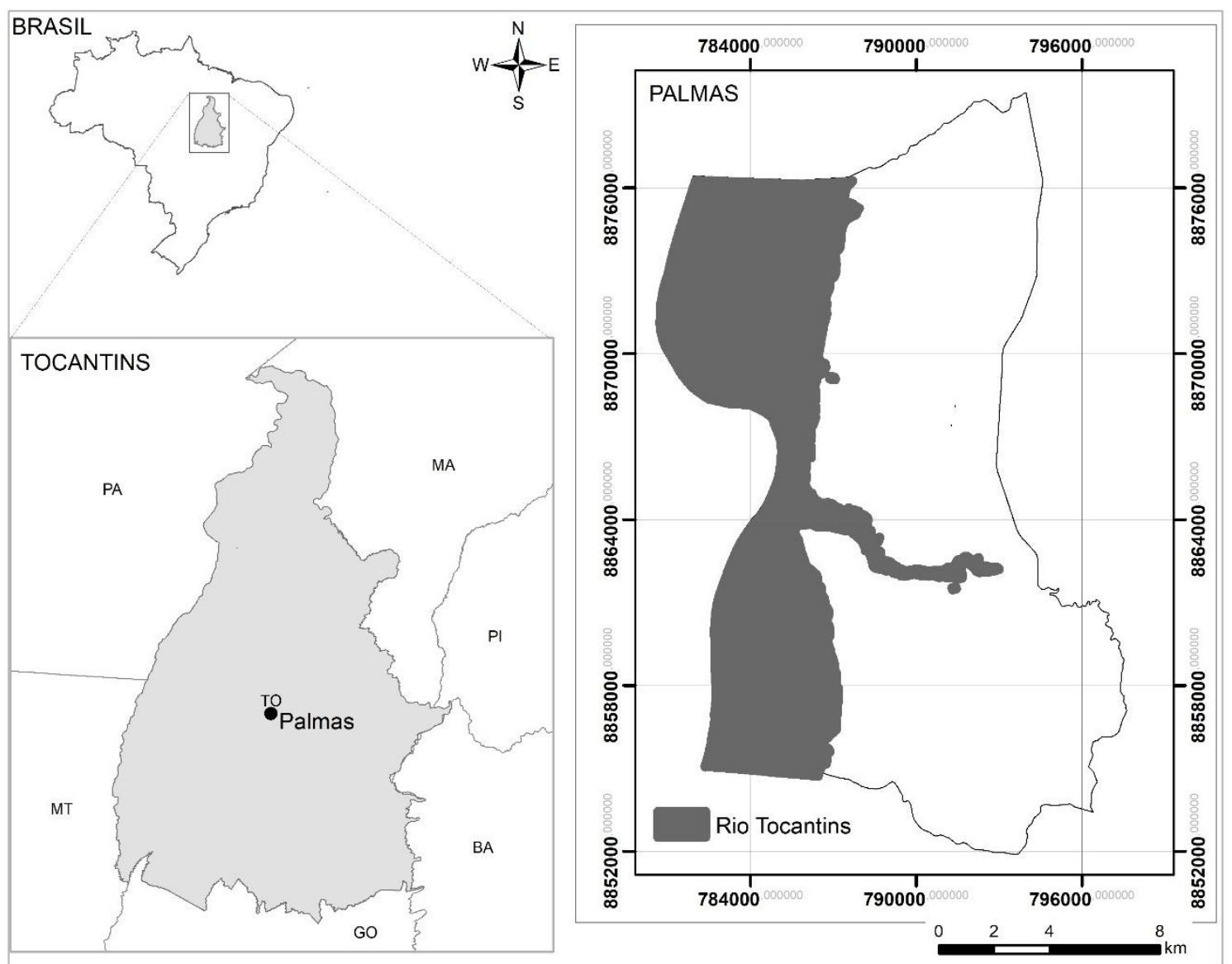

Figura 1. Área de estudo, a cidade de Palmas, Tocantins. Fonte: os autores.

Do total de sua população 221.742 pessoas residiam na área urbana e somente 6.590 na área rural. De acordo ainda com os dados do [34], a população estimada, para o ano de 2020, é de 306.296 habitantes. A cidade de Palmas possui a segunda maior taxa de crescimento demográfico de capitais brasileiras, da ordem de $2,40 \%$, bem acima da média nacional que foi de $0,77 \%$. A cidade recebe pessoas de praticamente todos os estados, com destaque para seus estados vizinhos, especialmente dos estados do Maranhão, Pará e Piauí.

Idealizada arquitetonicamente sob o modelo do urbanismo moderno e contemporâneo seu sítio urbano foi inserido entre as encostas da Serra do Lajeado e a margem direita do rio Tocantins. Porém, segundo Bessa e Oliveira [35] a cidade vem cedendo espaço 
a um aspecto antagônico "de uma urbanização determinada e planejada às imprevisibilidades do mundo real". Imprevisibilidades estas, originadas especialmente pelas arbitrariedades do poder público e pelos interesses dos agentes do mercado imobiliário, que extrapolou o que havia sido projetado inicialmente.

\subsection{Procedimentos metodológicos}

A metodologia envolveu a manipulação de duas imagens de sensoriamento remoto. Ambas correspondentes às imagens orbitais do satélite China-Brazil Earth Resources Satellite (CBERS-2B), provenientes do site do Instituto Nacional de Pesquisas Espaciais (INPE) e, referentes ao ano de 2010. A primeira corresponde a Câmera Multiespectral CCD, de resolução espacial de 20 metros e a segunda, a Câmera Pancromática HRC, de alta resolução espacial de 2,7 metros. A utilização das imagens obtidas por sensores de câmeras diferentes teve como intuito a aplicação da técnica de fusão. Tal técnica permitiu a obtenção de uma imagem sintética multiespectral com alta resolução espacial, ou seja, de uma imagem colorida com resolução espacial melhorada. De acordo com Leonerdi et al. [36] as técnicas de fusão de imagens possibilitam integrar a melhor resolução espacial da banda pancromática com a melhor resolução espectral das demais bandas, resultando em uma imagem colorida que reúne ambas as características.

Para tanto utilizou-se o Sistema de Processamento de Informações Georeferenciadas (SPRING), versão 5.4.3, que é um programa de Sistema de Informações Geográficas (SIG) e de Processamento Digital de Imagens (PDI), desenvolvido pelo Instituto Nacional de Pesquisas Espaciais (INPE).

As imagens obtidas, sem custos, precisaram ser submetidas ao processamento digital de imagens, que pode ser dividida em cinco etapas, resumidas no fluxograma da Figura 2. A importância dessa metodologia, e de suas etapas, advém do fato de que com as imagens coloridas eleva-se o contraste de cores para discernimento dos alvos urbanos.

A primeira etapa é destinada à obtenção das imagens, com data de passagem definida em função do último censo demográfico brasileiro, que foi no ano de 2010. Desse modo, como referido, adquiriu-se as imagens do CBERS-2B, sensores CCD e HRC, de 26 de junho de 2010 e, conforme, características descritas na Tabela 1.

Tabela 1. Dados orbitais utilizados na análise.

\begin{tabular}{llll}
\hline $\begin{array}{l}\text { Satélite } \\
\text { 2B }\end{array}$ & CBERS & Bandas & $\begin{array}{l}\text { Resolução } \\
\text { espacial }\end{array}$ \\
\hline CCD & 2,3 e 4 & 20 metros & Órbitas/Ponto \\
HRC & 1 & 2,5 metros & 159_111 e 159_C_111_5 e 159_C_112_1 \\
\hline
\end{tabular}

A imagem do sensor HRC foi registrada no Modo Tela, do SPRING, de acordo com a imagem do sensor CCD. Nesse modo, o analista associa a imagem a ser registrada, no caso a HRC com a imagem georreferenciada de referência, no caso a CCD. De modo geral, segundo a ajuda do SPRING, o registro estabelece uma relação entre coordenadas de imagem e coordenadas geográficas.

Isso será sempre necessário no processo de fusão de imagens desses dois tipos sensores, pois as mesmas não se sobrepõem, totalmente, na mesma área geográfica. Entretanto, para um bom resultado da fusão de imagens, é necessário que a faixa espectral da banda pancromática e das bandas multiespectrais tenham uma ampla área de interseção entre si. 


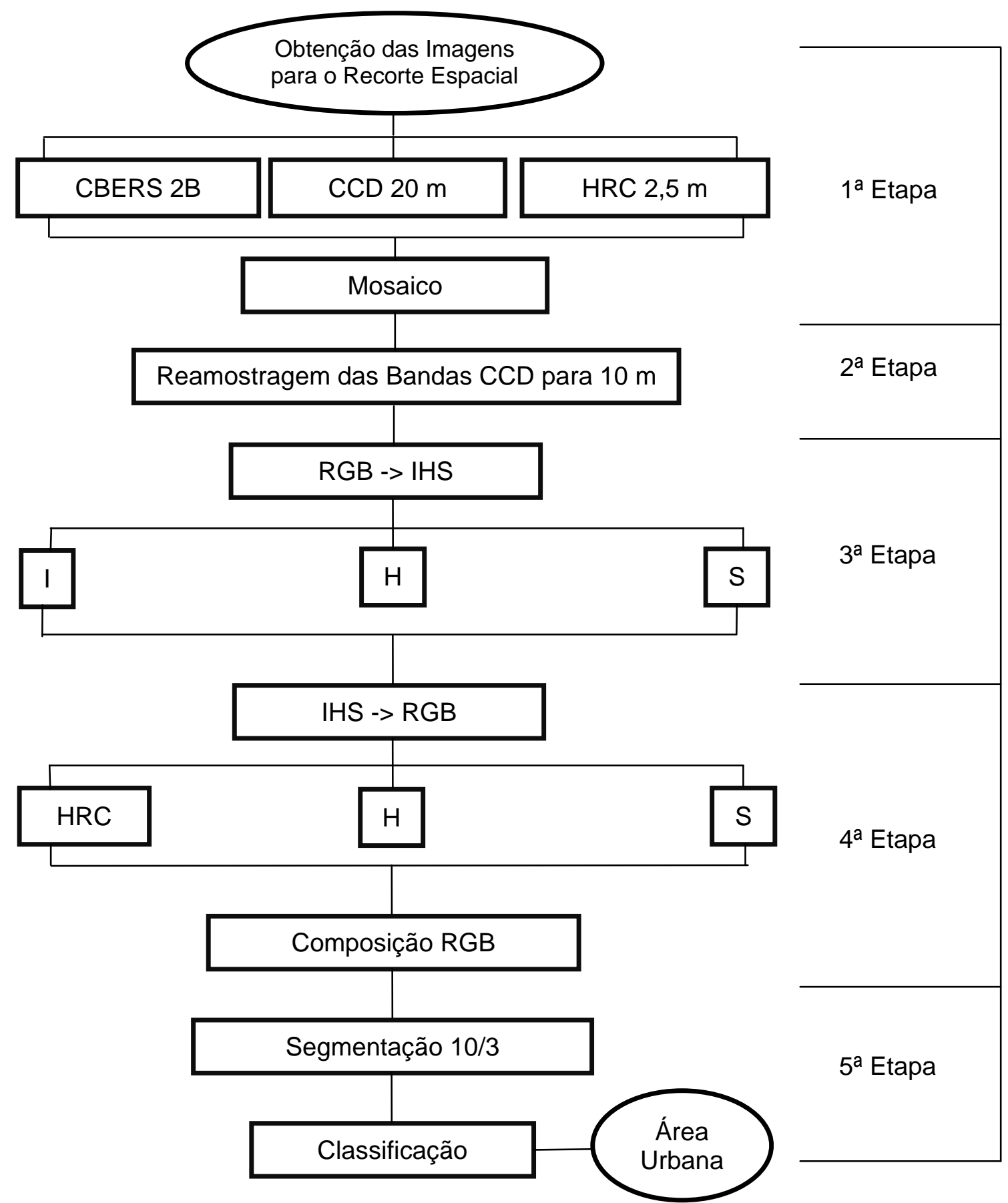

Figura 2. Fluxograma da metodologia do processamento digital de imagem.

Além do exposto, como a cidade de Palmas encontra-se em duas cenas (órbitas/ponto), foi necessária a realização do mosaico das mesmas. O mosaico de imagens serve para juntar ou unir, em um só arquivo, duas cenas ou mais, adjacentes. $\mathrm{Na}$ segunda etapa é necessária a reamostragem da imagem de maior resolução espacial, para evitar distorções, devido a grande diferença desta característica das imagens do sensor CCD em relação as do sensor HRC. Nessa aplicação, as bandas do sensor CCD foram reamostradas para 10 metros. Nessa técnica o analista cria os Planos de Informação (PI) ou camadas, atribuir a eles o valor de resolução de 10 metros. Na sequência importa para esse PI as imagens do sensor CCD. 
$\mathrm{Na}$ terceira etapa foi aplicado a transformação IHS (Intensity-Hue-Saturation), como uma das possibilidades de fusão de imagens. De forma geral, a fusão IHS busca o melhoramento da resolução espacial de imagem, por meio da integração da composição RGB à informação espacial da banda pancromática. A fusão, procedimento utilizado nessa análise é aplicada para melhorar a resolução espacial e isso influencia no detalhamento dos alvos na imagem [37].

Deste modo, o método IHS transforma uma imagem de três bandas de baixa resolução, como componentes de saturação vermelho $(R)$, verde $(G)$ e azul $(B)$ para intensidade (I), matiz $(\mathrm{H})$ e saturação $(\mathrm{S})$, em que I se refere ao brilho total da imagem; $\mathrm{H}$ ao dominante ou médio comprimento de onda da luz que contribui para a cor e; $\mathrm{S}$ para a pureza da cor [38]. Após esse procedimento, realiza-se o processo inverso, IHS para RGB.

Assim, na Quarta etapa o componente de intensidade é substituído por uma imagem de alta resolução espacial [39]. O resultado desse processo é a associação das cores das imagens multiespectrais à banda de alta resolução espacial, criando-se um novo conjunto de três bandas que podem ser utilizadas no processo de mapeamento de uso e da cobertura da terra. Ainda nessa etapa foi elaborado a composição de imagens, nesse caso R (Banda 2), G (Banda3) e B (Banda 4).

Na quinta e última etapa, realizou-se a classificação pelo método supervisionado por região, para discriminação da área urbana, ou seja, àquela onde as pessoas realmente vivem. $\mathrm{Na}$ classificação por região é necessária a segmentação de imagens. Assim, através de nossas experiências de classificação de imagens em áreas urbanas, via ferramentais do Spring, adotou-se o ISOSEG como o classificador a ser utilizado. O classificador ISOSEG é um algoritmo de agrupamento de dados nãosupervisionado, aplicado sobre o conjunto de regiões, que por sua vez são caracterizadas por seus atributos estatísticos de média, matriz de covariância, e também pela área [40]. Após a classificação realizou-se a função de "Mapeamento para Classes Temáticas". Nessa função, o analista pode converter a imagem classificada numa "imagem temática". A "imagem temática" pode ser convertida em vetores.

Os vetores, como arquivo de saída da classificação pode ser filtrado pelo campo da tipologia "urbano", da tabela de atributos do mapa de uso e cobertura da terra. Por fim, os vetores de saída devem ser editados, de modo a excluir áreas como shoppings, supermercados, hospitais, universidades, dentre outras, que apesar de serem áreas urbanas, não são utilizadas como habitações.

A partir da filtragem dos vetores das áreas onde as pessoas realmente residem, avançou-se para a estruturação do mapa de densidade demográfica pelo Método Dasimétrico. Desse modo, produziu a intersecção entre a área urbana e os polígonos dos setores censitários, conforme descrito por [31]. Na sequência, pode-se calcular as áreas da classe urbano em cada setor censitário e aplicar a Equação 1 para cálculo da densidade demográfica.

$$
\mathrm{Dd}=\mathrm{Pt} / \mathrm{Asc}
$$

Em que,

$\mathrm{Dd}=$ Densidade demográfica

$\mathrm{Pt}=$ População total

Asc = área total do setor censitário 
Neste trabalho, para efeitos de comparação, elaborou-se também o mapa de densidade demográfica da cidade de Palmas, pelo Método Coroplético, conforme indicações de [31]. Ambos, os mapas, foram elaborados sob regras da Semiologia Gráfica, conforme a metodologia apresentada por [41], para facilitação da leitura dos mapas.

\section{Resultados e Discussão}

O principal resultado da análise coloca em evidência a aplicação do sensoriamento remoto à um dos aspectos mais recorrentes, da análise geográfica, em estudos urbanos, a densidade demográfica. Desse modo, acredita-se que, sem as atuais tecnologias de processamento de imagens de sensoriamento remoto, seria inexequível a aplicação do método aqui apresentado.

De modo geral, os resultados revelaram que as áreas construídas, onde se localizam os habitats urbanos, encontravam-se dispersas na paisagem urbana de Palmas, para o período em análise. Com efeito, poucos eram os setores censitários, realmente ocupados por habitações. Esse dado revela como ocorria e ainda ocorre a reprodução do espaço na contemporaneidade, como realidade e como possibilidade.

Em Palmas, assim como em outras cidades brasileiras, esta característica está relacionada ao fenômeno da especulação imobiliária. Segundo Campos Filho [42], em termos gerais, a especulação imobiliária "é a forma pela qual os proprietários de terra recebem uma renda transferida dos outros setores produtivos da economia, especialmente através de investimentos públicos na infra-estrutura e serviços urbanos[...]", o que valoriza economicamente os espaços urbanos. No caso de Palmas, a especulação imobiliária ocorre, de acordo com [43], devido a um longo período de instabilidade econômica nacional, em que o investimento em terra se tornou uma segurança contra a descapitalização. Assim, as pessoas investiram em lotes, mas não os ocupavam de fato 3). Como reflexo e ainda segundo [43] "a capital tocantinense apresenta hoje um dos maiores índices de áreas não ocupadas, se comparada às demais capitais brasileiras, sobretudo em sua área central". Isso foi identificado no ano de 2020 (Figura 3).

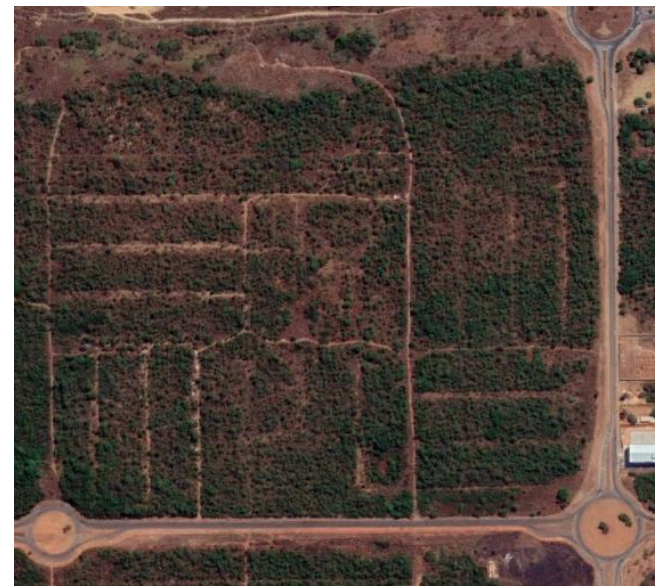

Figura 3. Quadra 703 Sul, desabitada. Fonte: Imagem Google Earth Pró, ano de 2020.

Sob a perspectiva do Método Dasimétrico, essa aplicação revelou resultados de densidades demográficas mais realísticas com tendência de aumento do teor de seus valores, conforme já revelado por [30-32]. O detalhamento dos alvos nas imagens processadas pelo método de fusão foi maior, o que contribuiu para a melhor precisão dos resultados. 
Como referido, para efeito de comparação, a Figura 4 apresenta a densidade demográfica pelo Método Coroplético. Assim, como já esperado observou-se que a densidade mapeada deu "[...] a impressão de que a população está distribuída homogeneamente em cada unidade de área, no caso os setores censitários, mesmo quando partes da região são, na realidade, desabitadas" [31].

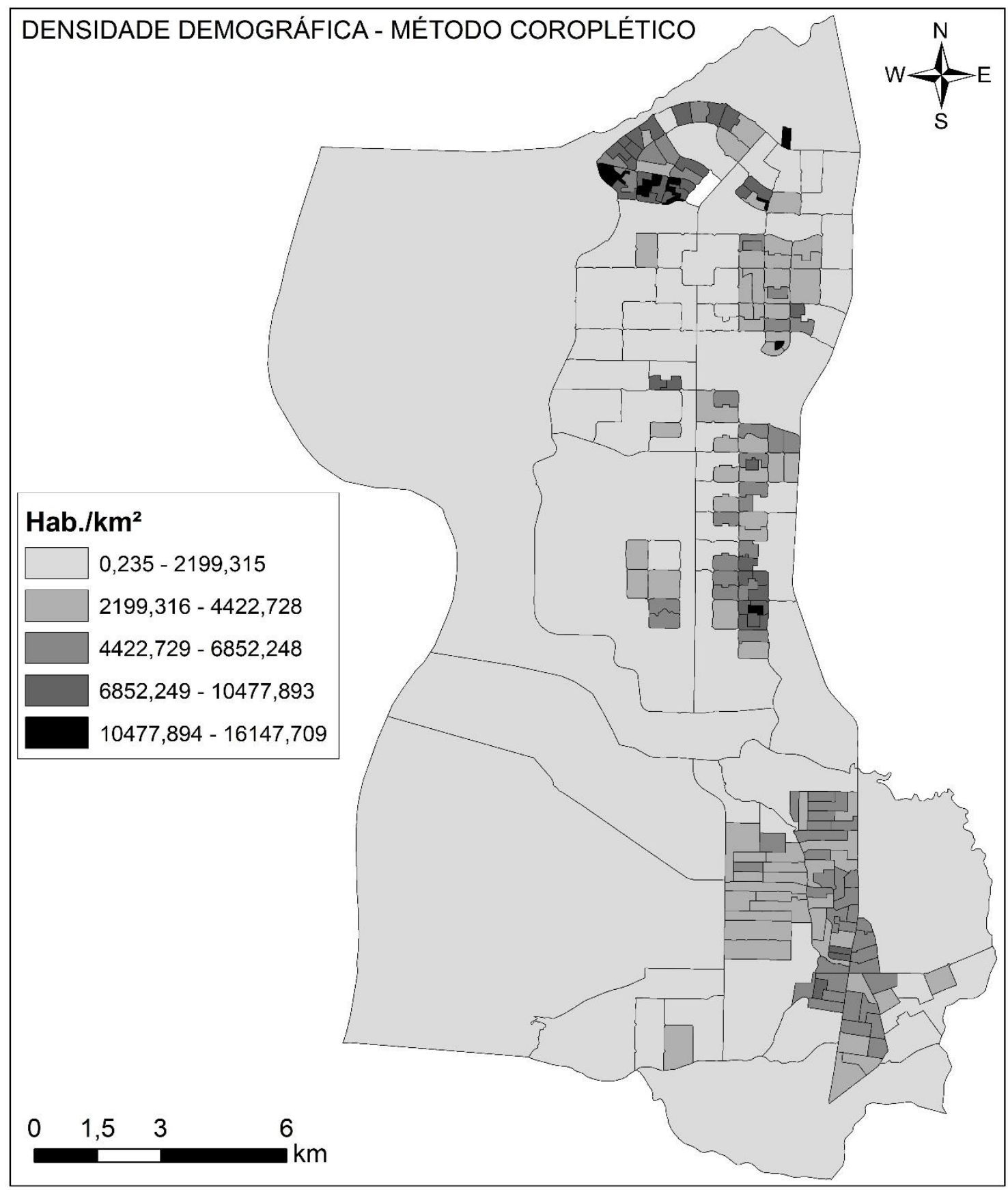

Figura 4. Densidade demográfica pelo Método Coroplético.

Para a cidade de Palmas, essa análise é importante, pois é sabido da existência da extensa área de alagamento resultante do barramento das águas do Rio Tocantins. Fato que pode ser visualizado no sentido norte e sul, do lado esquerdo da Figura 4 (comparar com Figura 1), que ocupa $30,61 \%$ da área total da cidade e que devia possuir valor igual a zero de densidade demográfica. Além disso, a cidade de Palmas 
possuí muitas áreas verdes especiais como: parques urbanos e Áreas de Preservação Ambiental - APA.

A Figura 5 revela a densidade demográfica pelo Método Dasimétrico. Assim, como pode ser observado, as áreas desocupadas dentro dos setores censitários não foram contabilizadas (áreas vazias) na análise, o que resultou no aumento dos valores da densidade demográfica das áreas ocupadas. Apesar disso, o que existe de comum entre os dois mapeamentos é o fato da ocupação dispersa ou fragmentada na paisagem da cidade de Palmas. Nesse sentido, [43] esclarece que o projeto inédito de planejamento da cidade de Palmas, mesmo que sob a perspectiva inovadora, com domínio de sua ocupação, não evitou a especulação imobiliária sem limites na cidade. $O$ resultado de toda esta falta de relação entre o planejado e o executado foi a exclusão social [43].

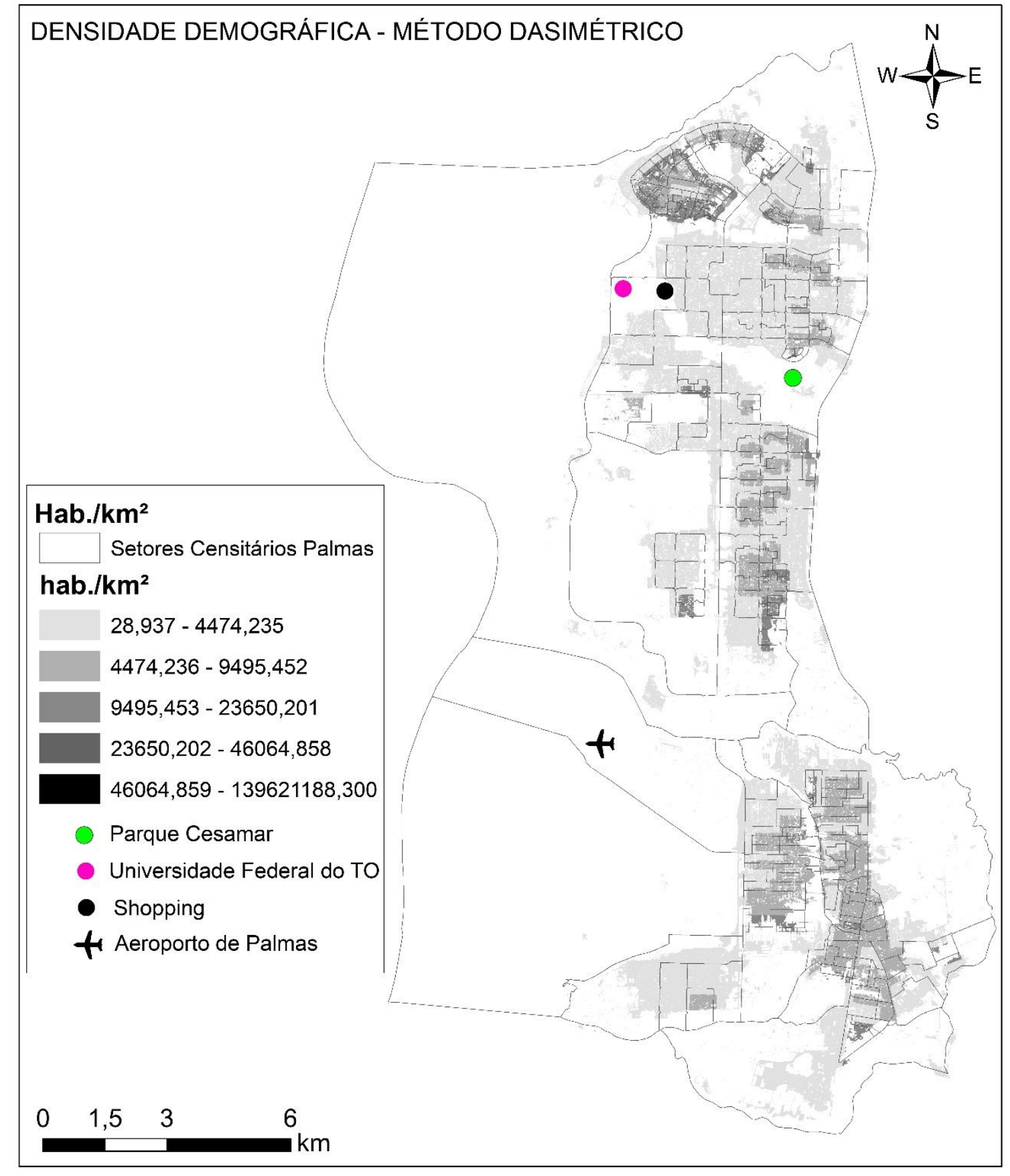

Figura 5. Densidade demográfica pelo Método Dasimétrico. 
Além do exposto, verificou-se que as maiores densidades ocorrem na porção norte, conhecida como Plano Diretor Norte e na porção central, nos arredores de áreas de lazer, como o Parque Cesamar. Nessa área identifica-se a maior verticalização da cidade, com presença de edifícios residenciais.

De modo geral, os mapas de densidade demográfica são úteis para estudos em geografia. Serve ao planejamento, ordenamento e reordenamento territorial, e as pesquisas sobre a relação entre superfícies impermeáveis e número de habitantes [44]. Além disso, a análise de densidade demográfica é processo básico no planejamento de transportes, pois fornece dados do provável quantitativo de passageiros [45]. Os adensamentos populacionais geram diferentes padrões de viagens, e sua análise pode ser aplicada também aos estudos de danos causados por desastres naturais, tais como terremotos [45], dentre outros.

Uma comparação mais detalhada está apresentada na Figura 6 (A e B). Na Figura 6A é apresentada a densidade pelo Método Dasimétrico, em que o número de habitantes de 1.120 habitantes foi dividido pela área urbana de $0,10 \mathrm{~km}^{2} \mathrm{o}$ que resultou em densidade de $11.178 \mathrm{hab} . / \mathrm{km}^{2}$. A Figura 6B apresenta os mesmos 1.120 habitantes, contudo, numa área de $0,29 \mathrm{~km}^{2}$, o que resultou em densidade de $3.813 \mathrm{hab} . / \mathrm{km}^{2}$.

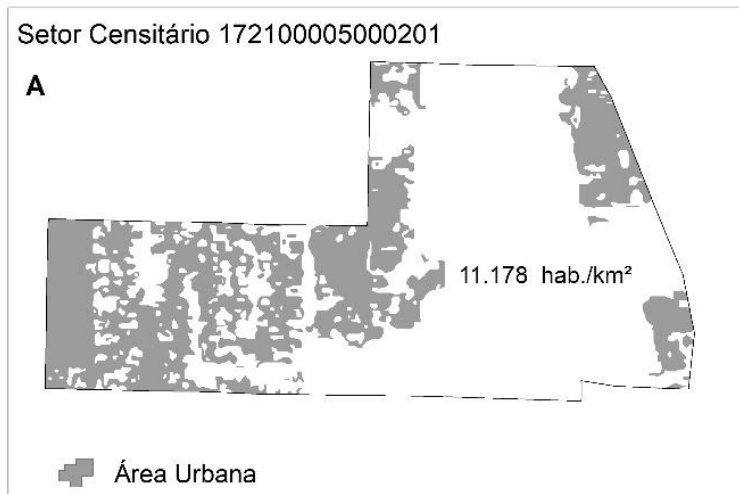

Figura 6. Densidade demográfica pelo Método Dasimétrico $(5 \mathrm{~A})$ e pelo Método Coroplético (5B). Fonte: os autores.

Nesse sentido, foi possível constar que a área ocupada por construções, consideradas para o cálculo da densidade por Dasimetria foi de $63,57 \mathrm{~km}^{2}$, ou seja, $22,15 \%$ da área da cidade de Palmas. Pelo Método Coroplético, a área considerada foi a área total da cidade, que é de 286,96 km². Mesmo com o refinamento da área calculada, acreditase que esse valor seja elevado, pois pequenas empresas podem ser incorporadas erroneamente como áreas habitadas. Essa restrição é considerada normal, já que, por sensoriamento remoto é inviável a distinção da destinação de um imóvel.

Além dos resultados, dessa análise, Santos et al. [31] revelaram que os resultados do cálculo de densidade demográfica estão diretamente relacionados ao tipo de imagem utilizada. Nesse sentido, concluíram que o mapeamento, a partir de fotografias aéreas, revelou áreas urbanas com maior detalhe, e, portanto, densidades demográficas mais realísticas. Soma-se as fotografias aéreas as imagens obtidas por Veículos Aéreos Não Tribulados (VANTs). Apesar dessa possibilidade, fotografias aéreas e imagens de VANTs são mais caras e exigem maior esforço computacional.

Ademais, uma das principais limitações e que compromete a atualização dos estudos de densidade demográfica, por qualquer método a ser utilizado, diz respeito ao fato de que essas análises dependem de dados do censo. No contexto atual, tem-se 
observado que o Brasil enfrenta dificuldades de realizar os trabalhos de recenseamento, referente ao ano de 2020. Este já deveria estar pronto, ou em fase de finalização, porém teve suas atividades comprometidas por decisões políticas e pela pandemia do novo coronavírus (SARS-CoV-2).

\section{Conclusão}

As ações mais relevantes, em resposta ao objetivo estabelecido, foram: a) o alto potencial da aplicação do sensoriamento remoto a um dos aspectos mais recorrentes de análise na Geografia, a densidade demográfica, para estudos urbanos e; b) o detalhamento da análise em escala intraurbana na cidade de Palmas. Os resultados corroboraram para uma melhor compreensão da ocupação na cidade, revelando o processo de espraiamento urbano, presente em muitas cidades brasileiras. Portanto, a metodologia pode ser replicada para outras cidades, sem restrição de área e quantidade de habitantes, de modo a oferecer elementos para os estudos em escalas de detalhe.

Apesar do foco na análise do padrão de ocupação da cidade de Palmas, através da análise intraurbana, os mapeamentos de densidade demográfica podem ser aplicados também aos estudos de planejamento de infraestrutura (escolas, transporte público, pavimentação). Além disso, podem ser aplicados aos estudos de avaliação de impactos ambientais, sociais e econômicos.

Para finalizar pode-se pensar os resultados deste trabalho no âmbito das políticas públicas brasileiras, tendo como foco o órgão responsável pela coleta, análise e publicação dos resultados dos levantamentos censitários brasileiros, o IBGE. Assim, sugere-se que sejam desvinculadas as operações de coleta (setores censitários) e disponibilização dos dados. Essa última deve compor os resultados por meio de uma máscara de uso urbano com cobertura nacional. Tal máscara contendo todas as áreas urbanas brasileiras seria submetida ao processo de recorte obedecendo aos limites de cada setor censitário. Desse modo, os vetores recebem dados coletados vinculados agora a uma extensão territorial que obedece aos limites de coleta, mas despreza áreas não habitadas de fato. Em princípio, acredita-se que essa proposta é viável, apenas considerando a área urbana, no entanto, procedimentos em escala nacional, para separar áreas comerciais de residenciais, ainda precisam ser melhor investigados.

\section{Recomendação aos leitores}

Adicionalmente os autores recomendam os vídeos intitulados "Mapa Dasimétrico Dasymetric Mapping" e "Mapa de Densidade Demográfica pelo Método Coroplético" disponíveis no Canal do YouTube ${ }^{\circledR}$ Geotecnologias na Rede, para aplicação da metodologia descrita nesse capítulo. O Canal do YouTube ${ }^{\circledR}$ Geotecnologias na Rede é uma iniciativa de um Projeto de Extensão da Universidade Federal de Goiás.

\section{Referências}

[1] Martinelli M., Graça, A. J. S. Cartografia Temática. Rev. Bras. Cartogr. [Internet]. 1 [citado 29o de novembro de 2020]; 67(4):913-28. Disponível em: <http://www.seer.ufu.br/index.php/revistabrasileiracartografia/article/view/49128>.

Acesso em: 01 de mar. 2021.

[2] Maantay J. A.; Maroko, Andrew R.; Herrmann, C. Mapping Population Distribution in the Urban Environment: The Cadastral-based Expert Dasymetric System (CEDS). 
Cartography and Geographic Information Science 2007; 34(2): 77-102. https://doi.org/10.1559/152304007781002190.

[3] Mennis J. Generating surface models of population using dasymetric mapping. The Professional Geographer 2003; 55(1): 31-42. https://doi.org/10.1111/0033-0124.10042.

[4] Monbeig P. Textos clássicos: o estudo geográfico das cidades. Cidades 2004; 1(2): 277-314. Disponível em:

<https://revista.fct.unesp.br/index.php/revistacidades/article/download/481/511>.

Acesso em: 09 de mar. 2021.

[5] Lefebvre H. O direito à cidade. 5a ed. São Paulo: Centauro Editora; 2008. 143 p. Disponível em: <http://www.arquicast.com/?feed-statsurl=aHR0cHM6Ly9tb25vc2tvcC5vcmcvaW1hZ2VzL2YvZmMvTGVmZWJ2cmVfSGVuc mlfT19kaXJlaXRvX2FfY2IkYWRILnBkZg\%3D\%3D\&feed-stats-url-post-id=208>. Acesso em: 09 de mar. 2021.

[6] Castells M. A questão urbana. Rio de Janeiro: Paz e Terra; 1983. 602 p.

[7] Sposito M. E. Capitalismo e Urbanização. São Paulo: Contexto; 1991.

[8] Carlos A.F.A. A cidade. São Paulo: Contexto; 1992.

[9] Corrêa R.L. O espaço urbano. São Paulo: Ática; 1989.

[10] Corrêa R.L. A rede urbana. São Paulo: Ática; 1989.

[11] Santos M. A urbanização brasileira. São Paulo: Hucitec; 1993.

[12] Santos M. Por uma economia política da cidade. São Paulo: Hucitec/EDUC; 1994.

[13] Pereira G.C., Silva B.C.N. Geoprocessamento e urbanismo. In.: Gerardi L.H. de O., Mendes I.A. (org.). Teoria, técnica, espaço e atividades. Temas de geografia contemporânea. Rio Claro: UNESP, AGTEO, 2001, p. 97-137.

[14] Moura A.C.M. Geoprocessamento na gestão e planejamento urbano. Belo Horizonte: Ed. Da autora; 2003.

[15] Moura A.C.M. Geoprocessamento na gestão e planejamento urbano. 3ª ed. Rio de Janeiro: Interciência; 2014.

[16] Leite M.E., Rosa R. Geografia e Geotecnologias no estudo urbano. Caminhos de Geografia 2006; 17(17): 180 - 186.

[17] Almeida, C. M. Aplicação dos sistemas de sensoriamento remoto por imagens e o planejamento urbano regional. arq.urb 2010; 3: 98-123. Disponível em: <https://revistaarqurb.com.br/arqurb/article/view/120>. Acesso em: 09 de mar. 2021.

[18] Filho J.A. de M., Silva J.X. da. Geoprocessamento aplicado à segurança e à qualidade de vida na Região da Tijuca (Rio de Janeiro). In.: Silva J.X. da, Zaidan R.T. (org.) Geoprocessamento \& meio ambiente. Rio de Janeiro: Bertrand Brasil, 2011.

[19] Martins M.H., Morato R.G., Kawakubo F.S. Mapeamento de Superfícies Impermeáveis Utilizando Ortofotos, Imagens de Satélite e Regressão Linear. Revista 
do Departamento de Geografia 2018; 35: 91-101. https://doi.org/10.11606/rdg.v35i0.131542.

[20] Portis G.T., Santos A.M. dos., Nunes F.G. Análise espaço temporal da alteração do uso do solo sob influência de um polo gerador de viagens em Goiânia, GO, Brasil. Ambiente construído 2020; 20(3): 513:525. https://doi.org/10.1590/s167886212020000300442 .

[21] Santos R.L. Nunes F.G. Mapeamento da expansão urbana e dos vetores de crescimento no município de Imperatriz - MA. Revista Espaço e Geografia 2020; 23(1): 209:234. Disponível em:

http://www.lsie.unb.br/espacoegeografia/index.php/espacoegeografia/article/view/698 Acesso em: 09 de mar. 2021.

[22] Batty M., Couclelis H., Eichen M. Urban systems as cellular automata. Environment and Planning B: Planning and Design 1997; 24: 159-164. https://doi.org/10.1068/b240159.

[23] Silva E.A. Cenários da Expansão Urbana na Área Metropolitana de Lisboa. Revista de Estudos Regionais 2002; (5):23-41. Disponível em: $<$ https://www.ine.pt/ngt_server/attachfileu.jsp?look_parentBoui=107014\&att_display=n \&att_download=y>. Acesso em: 09 de mar. 2021.

[24] Almeida C.M., Monteiro A.M.V., Camara G. Compêndio de curso sobre Modelos de Dinâmica Urbana: Conceitos, Derivação de Relações, Calibração, Exemplos; oferecido durante o XI Simpósio Brasileiro de Sensoriamento Remoto, Belo Horizonte MG. 2003. (Desenvolvimento de material didático ou instrucional - Compêndio de curso).

[25] Costa C.W., Dupas F.A., Cespedes J.G., Silva L.F. Monitoramento da expansão urbana, cenários futuros de crescimento populacional e o consumo de recursos hídricos no município de São Carlos, SP. São Paulo, UNESP, Geociências 2013; 32(1):63-80. Disponível em:

<http://www.ppegeo.igc.usp.br/index.php/GEOSP/article/view/7265>. Acesso em: 09 de mar. 2021.

[26] Massabki J.A.R., Peixoto A.S.P., Kaiser I.M., Manzato G.G. Modelagem dos padrões da expansão urbana da Região Metropolitana de São Paulo baseada em Autômatos Celulares. Urbe. Revista Brasileira de Gestão Urbana 2017; 9:362 - 371. https://doi.org/10.1590/2175-3369.009.supl1.ao08.

[27] Holt J.B., Lo C.P., Hodler T.W. Dasymetric estimation of population density and areal interpolation of census data. Cartography and Geographic Information Science 2004; 31:103-21. https://doi.org/10.1559/1523040041649407.

[28] Bielecka E. A dasymetric population density map of Poland. In: Proceedings of the 22nd International Cartographic Conference, A Coruna, Spain. 2005, July 9-15. Disponível em:

<https://www.cartesia.org/geodoc/icc2005/pdf/oral/TEMA5/Session\%209/ELZBIETA\%2 OBIELECKA.pdf>. Acesso em: 15 de mar. 2021.

[29] Mennis J. Dasymetric Mapping for Estimating Population in Small Areas. Geography Compass, 2009, 3: 727-745. Disponível em: https://doi.org/10.1111/j.17498198.2009.00220.x. Acesso em: 13 de maio 2016. 
[30] Lopes J.M.A., Santos A.M. Metodologia para Estruturação de Mapa Dasimétrico: Análise de densidade demográfica do Censo de 2010 para cidade de Ji-Paraná (RO). In: I Encontro Nacional de Geografia. Colonização, Território e Meio Ambiente em Rondônia, 2013.

[31] Santos A.M., Homes D.C.S.C., Ramos H.F. Densidade demográfica: um estudo comparativo de duas metodologias a partir de imagens orbital e suborbital na cidade de Aparecida de Goiânia/Goiás. Ateliê Geográfico 2018; 12(1): 175-200. https://doi.org/10.5216/ag.v12i1.45968.

[32] Ramos H.F., Santos A.M., Nunes F.G. Dasimetria aplicada à análise espacial da ocupação humana na cidade de Acreúna - Goiás. XVII Simpósio Brasileiro de Sensoriamento Remoto - SBSR, Anais. João Pessoa-PB, Brasil, 25 a 29 de abril de 2015, INPE. Disponível em: <http://www.dsr.inpe.br/sbsr2015/files/p0805.pdf>. Acesso em: 11 de jan. 2016.

[33] IBGE Instituto Brasileiro de Geografia e Estatística. Censo Demográfico ano 2010. Disponível em: <http://censo2010.ibge.gov.br/> Acesso em: 17 de nov. 2020.

[34] IBGE Cidades. <https://cidades.ibge.gov.br/> Acesso em 17 de nov. 2020.

[35] Bessa K., Oliveira C.F.P. Ordem e deserdem no processo de implantação de Palmas: a capital projetada do Tocantins. Geousp - Espaço e Tempo (Online) 2017; 21(2): 497-517. https://doi.org/10.11606/issn.2179-0892.geousp.2017.117161.

[36] Leonerdi F., Oliveira C.G., Fonseca L.M.G., Almeida C.M. Fusão de Imagens CBERS 2B: CCD-HRC. In: Simpósio Brasileiro de Sensoriamento Remoto (SBSR); 2530 Abril 2009; Natal, Brasil: INPE, 2009. p. 6951-6958.

[37] Colditz R., Wehrmann T., Bachmann M., Steinnocher K., Schmidt M., Strunz G, Dech S. Influence of image fusion approaches on classification accuracy: a case study. International Journal of Remote Sensing 2007; 27(15): 3311-3335. https://doi.org/10.1080/01431160600649254.

[38] Ehlers M., Klonus S., Astrand P.J, Rosso P. Multi-sensor image fusion for pansharpening in remote sensing. International Journal for Image and Data Fusion 2010; 1(1): 25-45. https://doi.org/10.1080/19479830903561985.

[39] Abdikan S., Sanli F.B. Comparison of different fusion algorithms in urban and agricultural areas using sar (palsar and radarsat) and optical (spot) images. Boletim de Ciências Geodésicas 2012; 18(4): 509-531. https://doi.org/10.1590/S198221702012000400001.

[40] Camara G., Souza R.C.M., Freitas U.M., Garrido J. Spring: Integrating remote sensingand GIS by object-oriented data modelling. Computers \& Graphics 1996; 20(3): 395-403. https://doi.org/10.1016/0097-8493(96)00008-8.

[41] Menezes P.M.L., Fernandes M.C. Roteiro de Cartografia. São Paulo: Oficina de Textos, 2013.

[42] Campos Filho, C. M. Cidades brasileiras: seu controle ou o caos. 4 ed. São Paulo: Studio Nobel, 2001. 
[43] Brito E.P. Planejamento, especulação imobiliária e ocupação fragmentada em Palmas. Caminhos de Geografia Uberlândia 2010; 11(34): 94-104. Disponível em: <http://www.seer.ufu.br/index.php/caminhosdegeografia/article/view/16161>. Acesso em: 09 de mar. 2021.

[44] Azar D., Graesser J., Engstrom R., Comenetz J., Leddy Jr R. M., Schechtman N.G.; Andrews T. Spatial refinement of census population distribution using remotely sensed estimates of impervious surfaces in Haiti. International Journal of Remote Sensing 2010; 31(21): 5635-5655. https://doi.org/10.1080/01431161.2010.496799.

[45] Su H., Wei H., Zhao J. Density effect and optimum density of the urban population in China. Urban Studies 2016; 54(7):1-18. https://doi.org/10.1177/0042098015624839.

\section{Autores}

Alex Mota dos Santos ${ }^{1, \star}$, Fabrizia Gioppo Nunes ${ }^{2}$, Rodrigo Lima Santos ${ }^{2}$

1. Curso de Engenharia de Transportes, Universidade Federal de Goiás, Rua Mucuri, Área III, 74.968-755, Aparecida de Goiânia, Brasil.

2. Instituto de Estudos Socioambientais, Universidade Federal de Goiás, Avenida Esperança s/n, Campus Samambaia, 74.690-900, Goiânia, Brasil.

* Autor para correspondência: alex.geotecnologias@gmail.com 